\title{
ÍNDICE DE PREVISÃO DE PRODUÇÃO DE LEITE PARA VACAS JERSEY
}

\section{LUIZ A. LALONI ${ }^{1}$, IRENILZA A. NÄÄS ${ }^{2}$, MARCOS MACARI ${ }^{3}$, DANILO F. PEREIRA ${ }^{4}$, MARIA DAS G. PINHEIRO}

RESUMO: No Brasil, o uso de vários modelos de criação intensiva e semi-extensiva desfavorece a adoção generalizada de métodos de manejo do gado bovino, principalmente do gado leiteiro. Mesmo assim, a produção leiteira pode ser melhorada a partir do uso de tecnologias que possam garantir o manejo adequado do rebanho. O objetivo deste trabalho foi desenvolver um índice de previsão de produção de leite para vacas Jersey em lactação, de genética de alta produtividade, em regime semiestabulado, nas condições tropicais. Para a obtenção do índice, consideraram-se a temperatura e a umidade relativa do ambiente e a velocidade do ar, assim como valores de precipitação pluviométrica, temperatura do solo do pasto e a radiação solar como agentes estressores, os quais podem alterar a produção de leite. O experimento considerou dois tratamentos: A - as vacas permaneceram em sala de espera guarnecida com chuveiro e ventiladores, por um período $30 \mathrm{~min}$ antes da ordenha; B - as vacas não tiveram acesso a essa sala de espera (controle). Fora do período de ordenha, as vacas tiveram acesso ao pasto. Observou-se que as diferenças de médias de produção entre os tratamentos não foram estatisticamente significativas. Foram procedidas as análises para efeito de elaboração do modelo e chegou-se a um modelo factível, considerando a relação entre produção e a precipitação, assim como a temperatura máxima do solo do pasto.

PALAVRAS-CHAVE: bovinocultura de leite, ambiência animal, índice de produção.

\section{INDEX FOR PREDICTING MILK PRODUCTION IN JERSEY COWS}

SUMMARY: In Brazil the adoption of several models of cattle confinement leads to special conditions for management methods in dairy production, which can be improved by the use of technology that assures better herd management. Indexes relating environmental variables to production are applied for the prediction of milk production. The values of temperature and relative humidity, rain index, solar radiation and pasture soil temperature are generally considered potential stress agents for cows. The objective of this research was to develop an index for predicting milk production for high productivity Jersey milking cows lodged in semi confinement in tropical conditions. The experiment considered two treatments: A - the cows waited for 30 minutes prior to milking in a room with a shower associated to a fan; B - the cows did not have access to this room (control). Other than the waiting period, the cows had access to pasture. Differences in the effect of average production were not statistically significant. The analysis for studying the effect of the variables and designing the model led to a statistical model relating the variables milk production and rain index, as well as the maximum soil temperature of pasture, and milk production.

KEYWORDS: milk cattle, animal environment, production index.

\footnotetext{
${ }^{1}$ Professor da PUCCAMP, Campinas, SP Brasil. In memorian

${ }^{2}$ Profa. Titular, FEAGRI/UNICAMP, C. Postal 6011, Campinas - SP, Fone/Fax: (0XX19) 3788.1039, e-mail: irenilza@agr.unicamp.br

${ }^{3}$ Prof. Titular, FCAV/UNESP - Câmpus de Jaboticabal - SP.

${ }^{4}$ Doutorando, FEAGRI/UNICAMP, Campinas - SP.

${ }^{5}$ Pesquisadora do Instituto de Zootecnia do Estado de São Paulo, Ribeirão Preto - SP.

Recebido pelo Conselho Editorial em: 14-8-2001

Aprovado pelo Conselho Editorial em: 5-5-2004
} 


\section{INTRODUÇÃO}

No Brasil, a adoção de vários modelos de criação intensiva e semi-extensiva desfavorece a adoção generalizada de métodos de manejo do gado bovino, principalmente do gado leiteiro. Mesmo assim, a produção leiteira pode ser melhorada a partir do uso de tecnologias que possam garantir o manejo adequado do rebanho.

O gado Jersey transforma, de forma eficiente, as rações e a forragem em produção de leite, apresentando bom desempenho em instalações comerciais e em programas de pastoreio, requerendo menos área de pasto por vaca. À medida que se aumenta o índice de pastoreio, também aumenta o lucro por hectare (MORAES JÚNIOR, 1997).

De modo geral, a zona termoneutra para vacas holandesas, em lactação, varia de $4{ }^{\circ} \mathrm{C}$ a $26^{\circ} \mathrm{C}$ (HUBER, 1990). A temperatura crítica superior para vacas em lactação das raças Pardo-Suíça e Jersey pode chegar a 27 e $29^{\circ} \mathrm{C}$, respectivamente (HAFEZ, 1973), enquanto para a vaca Zebu a crítica superior seria de $30-35^{\circ} \mathrm{C}$ (BIANCA, 1965). Conforme NÄÄS (1998), a faixa de 13 a $18{ }^{\circ} \mathrm{C}$ é termicamente confortável para a maioria dos ruminantes, especificamente para as vacas em lactação, podendo essa faixa estender-se de 4 a $24{ }^{\circ} \mathrm{C}$, restringindo-se aos limites de 7 a $21{ }^{\circ} \mathrm{C}$ em função da umidade relativa do ar e da radiação solar.

Em Israel, verificou-se que a temperatura crítica superior, para vacas holandesas, altas produtoras, foi de 25 a $26^{\circ} \mathrm{C}$, independentemente de aclimatação prévia ou nível de produção. Até esse limite, as vacas conseguiram manter a estabilidade de temperatura corporal. $\mathrm{O}$ aumento da temperatura do corpo, quando os animais estiveram expostos a temperaturas acima da crítica superior, limitou a produção de leite e o desempenho reprodutivo (BUCKLIN \& BRAY, 1998).

JOHNSON (1965) fez uma tentativa para demonstrar a síndrome de adaptação geral com vacas em lactação, baseada nos princípios postulados por SELYE (1975). Assim, quando uma vaca em lactação é submetida a uma temperatura ambiente de $29^{\circ} \mathrm{C}$ (estresse pelo calor), logo após encontrar-se sob condições de termoneutralidade ou conforto $\left(18^{\circ} \mathrm{C}\right)$, sua reação é adaptar-se fisiologicamente ao estresse agudo, desencadeando a reação de alarme com uma acentuada queda na produção de leite. Após poucos dias, a recuperação da produção de leite é limitada, havendo uma tendência para estabelecer-se um nível de aclimatação, o qual está abaixo do potencial genético sob condições de termoneutralidade.

ZAPPAVIGNA (2002) aponta como fatores limitantes de construção de estábulos, em regiões de clima quente, a questão da radiação solar. Esse autor mencionou que o telhado influiu negativamente no balanço final das cargas térmicas, enquanto o piso influenciou positivamente por promover a remoção de calor na forma latente quando umedecido. Em trabalho realizado por BACCARI JÚNIOR et al. (1983), com vacas holandesas em lactação, verificou-se que algumas imergiam os membros anteriores no bebedouro comum ou deitavam em poça de lama, mesmo durante um brando verão, como forma de aliviar o estresse térmico.

Vacas Jersey, sob temperatura ambiente média de $10^{\circ} \mathrm{C}$, apresentaram temperatura retal (TR) de $38,3^{\circ} \mathrm{C}$, enquanto a $35^{\circ} \mathrm{C}$ o valor correspondente de TR foi de $39,5^{\circ} \mathrm{C}$ (GAALAAS, 1960 , citado por DUKES, 1962). A hipertermia pode ocorrer a temperaturas ambientes relativamente baixas quando a umidade do ar é alta, a produção metabólica de calor é elevada, há altos níveis de nutrição e produção, ou ainda como resultado da gestação ou excitação (BIANCA, 1973). Durante o calor, vacas em lactação apresentam TR pouco mais elevada que vacas secas.

Muitos índices de estresse térmico vêm sendo utilizados em animais, levando-se em conta a taxa respiratória, o volume de ar respirado, a pulsação, a temperatura de superfície corporal, a temperatura corporal interna, o nível de atividade, o tipo de cobertura do corpo e outras características fisiológicas. A temperatura do corpo, a taxa respiratória e o volume de ar respirado são as respostas ao estresse térmico 
mais utilizadas, isoladamente ou em combinação, para o desenvolvimento dos índices de conforto térmico (FEHR et al., 1983).

Índices de conforto térmico foram propostos na literatura e hoje estão sendo usados em todo o mundo, servindo de parâmetros para obter altas produtividades, já encontradas em produção intensiva de proteína animal das mais diversas espécies.

No Brasil, os índices de conforto térmico desenvolvidos em condições de clima temperado adotados para o gado leiteiro, em regime intensivo de estabulação, já estão parcialmente identificados; no entanto, há um significativo número de produtores utilizando a produção leiteira em sistema de semiestabulamento, ocorrendo, então, necessidade de estabelecimento de índices de conforto térmico ajustáveis a esses casos.

PICKERING (1982) apresentou modelos para análise do ambiente nos quais os elementos de entrada são as temperaturas de bulbo seco, sendo calculadas as radiações solar direta e difusa com os demais dados ambientais fornecidos ao modelo. PIMENTEL GOMES (1987) sugeriu que, dadas duas variáveis $\mathrm{X}$ e $\mathrm{Y}$, das quais $\mathrm{X}$ é fixada com grande exatidão, a teoria da regressão deve ser preferida como medida de dependência entre as variáveis, ao invés de coeficientes de correlação ou de determinação. Em casos de interesse científico em que não há possibilidade de repetições para os dados a serem coletados, como é o caso de variáveis meteorológicas, esse autor afirmou que a regressão polinomial pode ser realizada, com justificável aceitação, utilizando como resíduo o quadrado médio dos desvios da regressão.

Estudando uma adaptação do índice ETI (Equivalent Temperature Index) (BAÊTA, 1998) para vacas em semiconfinamento, LALONI (1997) encontrou que havia diferenças significativas entre os valores de ETI para vacas confinadas em freestall, quando comparadas com as mesmas vacas em semiconfinamento. Para ser desenvolvida uma equação matemática que refletisse o fenômeno, foram analisados os dados de baixa, média e alta produtividades.

O objetivo do presente trabalho foi desenvolver um índice de previsão de produção de leite que estivesse relacionado com variáveis ambientais, para vacas Jersey em lactação, de genética de alta produtividade.

\section{MATERIAL E MÉTODOS}

O projeto foi desenvolvido no Núcleo de Pesquisa Zootécnica Nordeste do Instituto de Zootecnia, Ribeirão Preto - SP, na latitude $21^{\circ} 11^{\prime}$ S e longitude $47^{\circ} 48^{\prime} \mathrm{W}$, com altitude média de $621 \mathrm{~m}$, no período de janeiro a maio de 1999. A precipitação pluviométrica média anual é igual a $1.416 \mathrm{~mm}$, com pico durante o verão, e a temperatura média anual do período foi $21,6 \pm 1,2{ }^{\circ} \mathrm{C}$, enquanto a umidade relativa média foi de $72 \pm 5 \%$. Durante o experimento, os dados de temperatura média máxima foram de $35,1{ }^{\circ} \mathrm{C}$ e média mínima de $21,5^{\circ} \mathrm{C}$. O tipo climático é Cwa, segundo a classificação de Köeppen, sendo caracterizado como clima tropical de altitude, com inverno seco e verão quente e chuvoso.

Foram utilizadas 29 vacas da raça Jersey, puras por origem (P.O.), em lactação, distribuídas em dois esquemas de manejo (A e B). No tratamento A, antes da ordenha, 14 vacas em lactação permaneceram por um período $30 \mathrm{~min}$, em média, em sala de espera guarnecida com chuveiro e ventiladores e, no tratamento B, 15 vacas em lactação não tiveram acesso a essa sala de espera (controle). As vacas foram ordenhadas duas vezes ao dia, com ordenhadeira mecânica. Fora do período de ordenha, os animais permaneceram em área sombreada, bosque natural, com livre acesso a piquetes de capim Tanzânia, em esquema de lotação rotacionada. Foi fornecida ração em cochos móveis, instalados no bosque, sendo composta basicamente de milho, farelo de soja, caroço de algodão e sorgo picado.

Os parâmetros ambientais, fisiológicos e comportamentais foram coletados, tanto no interior da sala de espera, como nas áreas externas de movimentação dos animais. As medidas das variáveis climáticas foram feitas diariamente, tanto no exterior como no interior das instalações, sendo as referentes ao 
ambiente externo obtidas junto ao Instituto Agronômico, distante aproximadamente $3 \mathrm{~km}$. Foi também coletada a temperatura de solo utilizando-se de um termômetro de mercúrio Incotherm ${ }^{\circledR}, \operatorname{com} 0,1^{\circ} \mathrm{C}$ de precisão. A coleta de dados foi feita diariamente de janeiro a maio de 1999, nos seguintes horários: 9; $11 ; 13 ; 15$ e $17 \mathrm{~h}$. As medições das temperaturas de bulbo úmido e bulbo seco foram feitas por meio de higrômetros digitais de marca Instrutherm ${ }^{\circledR}$, com precisão de $0,1^{\circ} \mathrm{C}$ e termômetros de mercúrio, colocados no centro geométrico da sala, a uma altura de $2,0 \mathrm{~m}$ do piso. $\mathrm{O}$ controle leiteiro foi feito durante cinco dias por semana, sendo medida a temperatura retal dos animais, utilizando-se de termômetro clínico após a segunda ordenha.

Para a análise e seleção das variáveis ambientais, que interferiram na produção de leite, utilizouse a Análise de Componentes Principais (PCA) (JOHNSON, 1998). As regressões aplicadas utilizaram modelos de efeito aleatório (JONES, 1993). As variáveis climáticas têm papel explanatório neste trabalho em termos de modelagem para previsão da produção de leite. Os modelos de previsão, em função de variáveis interdependentes, comportam-se melhor e apresentam resultados mais fidedignos quando se tem garantia da estrutura de correlação entre as variáveis explanatórias, sendo que, quanto menores forem essas correlações, melhor será o modelo ajustado.

Tratando-se de variáveis ambientais, pode-se imaginar que exista uma estrutura de correlação entre temperatura, radiação solar e umidade relativa. A escolha das variáveis deve depender dessa estrutura e, da mesma forma, a variável explanatória deve ser observada em uma amplitude que permita captar diferenças na resposta. Logo, por ter uma grande quantidade de variáveis ambientais, a técnica de Componentes Principais (JOHNSON, 1998) adaptou-se no estudo da estrutura de correlação e de uma pré-seleção das explanatórias.

Os dados foram analisados utilizando-se dos programas computacionais Statistica 5.1, Stata 5.0 e Spad 3.5.

\section{RESULTADOS E DISCUSSÃO}

Observou-se forte correlação entre as variáveis de Radiação (RADI, RADR) e a correlação dessas com as temperaturas, principalmente a temperatura máxima do ambiente (TAMAX) e do solo (TSIMAX). Também pôde-se observar a correlação entre as variáveis de temperatura, de forma mais marcante TAMIN e TSIMIN, ou seja, as temperaturas mínimas do solo e do ambiente estiveram altamente associadas.

A precipitação (PREC) e a temperatura máxima do solo (TS1MAX) mostraram-se independentes de todas as demais e mereceram destaque por esse fato. As demais variáveis não trouxeram grande contribuição na explicação do conjunto de dados ambientais, devido talvez à sua pequena amplitude. $\mathrm{Na}$ Tabela 1, apresentam-se as variáveis ambientais coletadas no local e regionalmente.

TABELA 1. Medidas descritivas das variáveis ambientais selecionadas.

\begin{tabular}{lccc}
\hline \multicolumn{1}{c}{ Variável Climática } & Média & Mínima & Máxima \\
\hline Radiação solar incidente $\left(\mathrm{W} \mathrm{m}^{-2}\right)$ RADI & $386,3 \pm 75,5$ & 121,7 & 504,3 \\
Radiação solar direta $\left(\mathrm{W} \mathrm{m}^{-2}\right)$ RADIR & $52,3 \pm 16,6$ & 3,0 & 80,6 \\
Temperatura máxima do ar $\left({ }^{\circ} \mathrm{C}\right)$ TAMAX & $32,0 \pm 3,0$ & 20,1 & 36,9 \\
Temperatura mínima do ar $\left({ }^{\circ} \mathrm{C}\right)$ TAMIN & $18,5 \pm 2,0$ & 8,2 & 21,0 \\
Temperatura máxima do solo $\left({ }^{\circ} \mathrm{C}\right)$ TS1MAX & $31,2 \pm 3,3$ & 24,0 & 35,8 \\
Temperatura mínima do solo $\left({ }^{\circ} \mathrm{C}\right)$ TS1MIN & $24,9 \pm 2,1$ & 16,7 & 28,0 \\
Precipitação $(\mathrm{mm})$ PREC & $7,0 \pm 11,6$ & 0 & 47,0 \\
\hline
\end{tabular}


O diagrama de correlação (Figura 1) é um resultado da PCA (Análise de Componentes Principais) que auxilia na interpretação da estrutura de correlação. Setas próximas (ângulo fechado entre as setas) e com boa representação indicam que as variáveis são correlacionadas positivamente entre si. Setas que formam ângulos próximos de $90^{\circ}$ indicam independência.

A precipitação (PREC) mostrou-se independente de todas as demais variáveis ambientais. Esse resultado concorda parcialmente com os de BUCKLIN \& BRAY (1998), que encontraram melhor resposta produtiva em vacas alojadas em ambientes com aspersão. Embora no presente estudo as vacas estivessem submetidas aos tratamentos somente antes da ordenha, durante o período de descanso estavam no pasto, logo, sujeitas à influência da precipitação pluviométrica, que ocorreu diariamente durante o experimento (Tabela 1).

Com exceção da temperatura máxima do solo e da precipitação, as outras variáveis não contribuíram na explicação do conjunto de dados climáticos. Após as análises descritas anteriormente e ajustes de modelos para cada variável ambiental, de acordo com as análises gráficas, chegou-se a dois modelos utilizando como preditoras as variáveis temperatura máxima do solo (TS1MAX), por meio de um modelo de regressão polinomial cúbico, e precipitação, por meio de um modelo de regressão simples.

Foram ajustadas as curvas de interpolação pelo Método dos Mínimos Quadrados Ponderados e, com exceção de precipitação (PREC), que praticamente não apresentou efeito, as demais apresentaram curvas que evidenciam uma função próxima de um polinômio de terceiro grau, ou (TS1MAX).

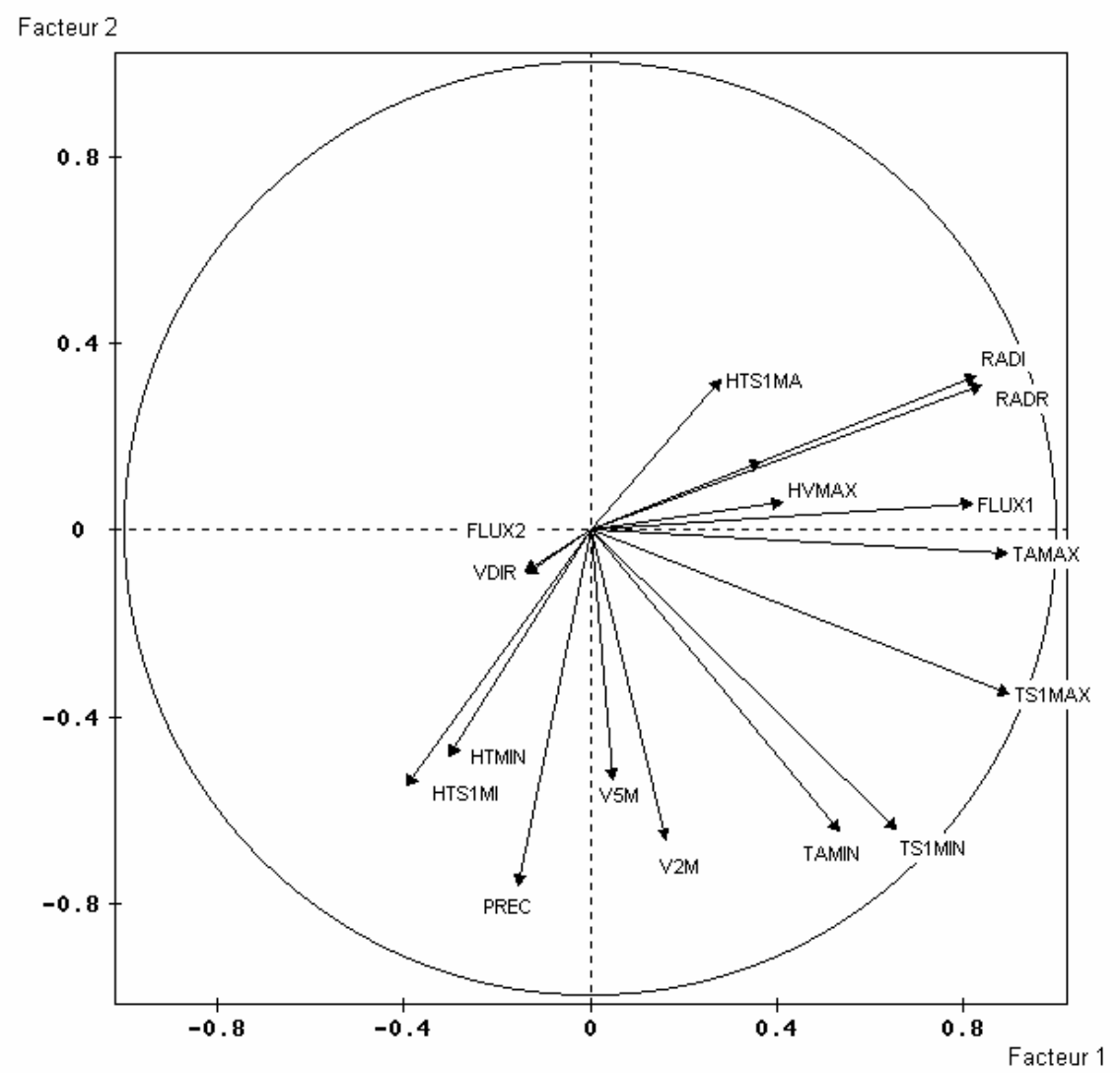

RADI = radiação solar incidente $\left(\mathrm{W} \mathrm{m}{ }^{-2}\right) ;$ RADIR $=$ radiação solar direta $\left(\mathrm{W} \mathrm{m}^{-2}\right) ;$ TAMAX = temperatura máxima do ar $\left({ }^{\circ} \mathrm{C}\right)$; TAMIN = temperatura mínima do ar $\left({ }^{\circ} \mathrm{C}\right)$; TS1MAX = temperatura máxima do solo $\left({ }^{\circ} \mathrm{C}\right)$; TSIMIN $=$ temperatura mínima do solo $\left({ }^{\circ} \mathrm{C}\right) ;$ PREC $=$ precipitação $(\mathrm{mm})$. Resultados impressos diretamente do programa computacional Stata 5.0

FIGURA 1. Diagrama de correlação das variáveis climáticas ( $1^{\circ}$ e $2^{\circ}$ eixos $)$. 
Nas temperaturas, principalmente nas máximas, observou-se aumento de produção média de leite de $1 \mathrm{~kg}$ nas temperaturas entre 30 e $34^{\circ} \mathrm{C}$, diferindo dos valores de produção apontados como limites da zona de termoneutralidade, por JOHNSON (1965), HAFEZ (1973), HUBER (1995), BUCKLIN \& BRAY (1998) e NÄÄS (1998). Entretanto, verificou-se que esse fato está relacionado diretamente com a precipitação pluviométrica que ocorreu diariamente logo após o acréscimo de temperaturas, durante todo o experimento, prevalecendo, portanto, no acréscimo da produção de leite, o efeito do resfriamento adiabático provocado pela chuva, concordando com BUCKLIN \& BRAY (1998), que demonstram o benefício do uso de água para resfriamento de vacas leiteiras.

Foi ajustado um modelo de regressão simples para produção de leite, em função da precipitação pluviométrica. O modelo estimado foi:

Produção de leite $=10,67+0,017$ (Precipitação)

Esse modelo indica uma tendência positiva da produção em função da chuva, para as vacas em pastoreio. O resultado pode ser visualizado na Figura 2. Essa tendência de acréscimo da produção de leite, em função do resfriamento adiabático, provocado pela evaporação de partículas de água contida no pelame, é parcialmente explicada por BACCARI JÚNIOR (1983) e ZAPPAVIGNA (2002).

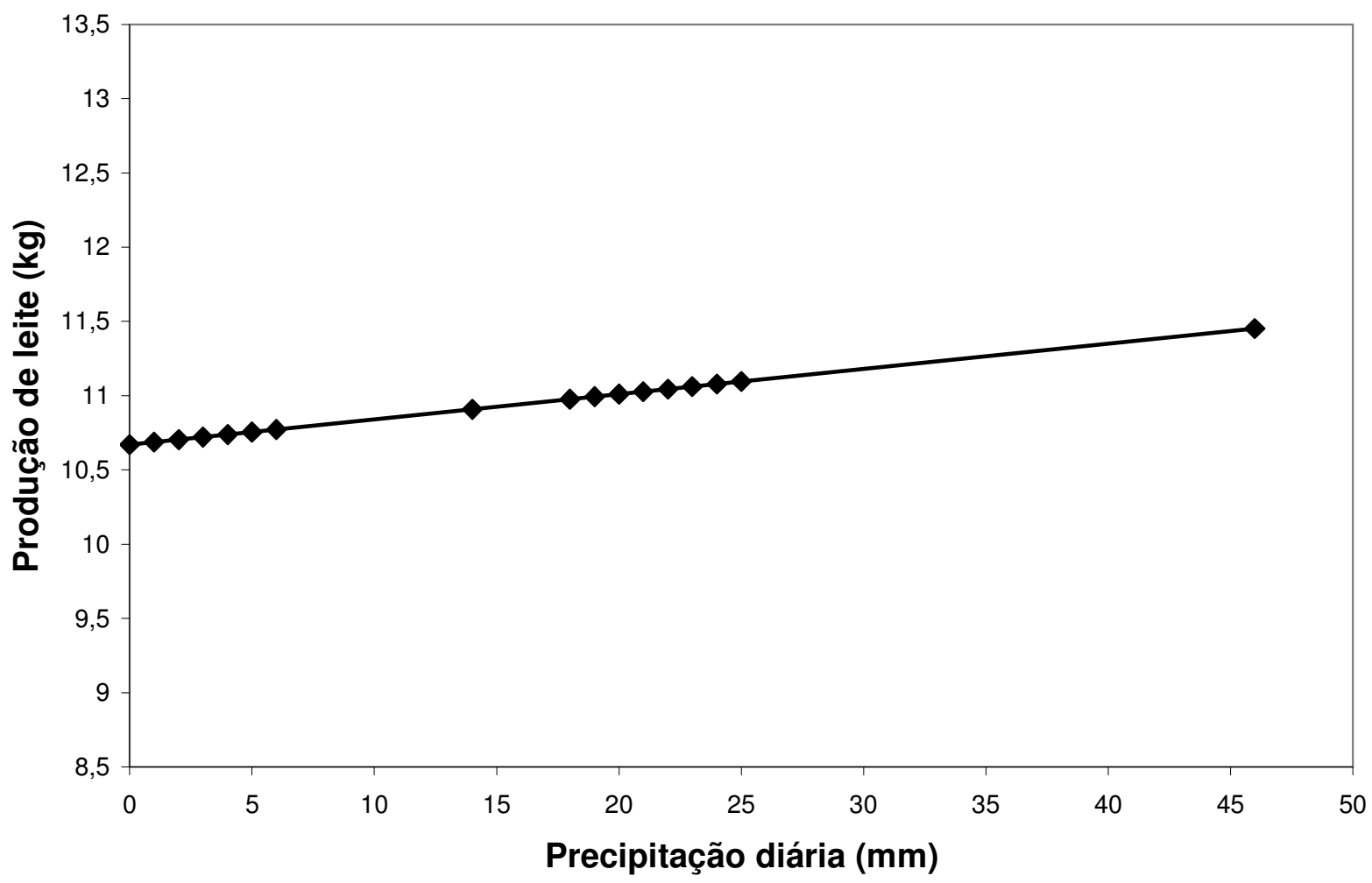

FIGURA 2. Produção estimada pelo modelo da eq.(1), em função da precipitação diária. Limite de confiança de $95 \%$ para os coeficientes.

$\mathrm{Na}$ Tabela 2, apresentam-se os coeficientes advindos da análise de regressão simples para o nível de significância de 5\%. O ganho medido na produção de leite foi de aproximadamente $1 \mathrm{~kg} \mathrm{em}$ relação às temperaturas menores que $30^{\circ} \mathrm{C}$, e cerca de $0,6 \mathrm{~kg}$ em relação à média geral estimada $(10,95 \mathrm{~kg})$, provavelmente devido ao resfriamento provocado pela chuva sobre as vacas em pastoreio. 
TABELA 2. Modelo de regressão simples de efeitos aleatórios para produção em função da precipitação.

\begin{tabular}{lcccc}
\hline Produção de Leite $(\mathrm{kg})$ & Erro-Padrão & $\mathrm{P}$ & \multicolumn{2}{c}{ Intervalo de Confiança de 95\% } \\
\hline Precipitação & 0,0088 & 0,050 & $-0,0003$ & 0,0345 \\
Constantes & 0,7561 & 0,000 & 9,1915 & 12,1553 \\
\hline
\end{tabular}

Como o efeito temperatura máxima do solo do pasto também apresentou relativa adequação da suposição de efeitos aleatórios na forma polinomial cúbica, foi ajustado um modelo de regressão para produção de leite, em função dessa variável. O modelo estimado foi:

Produção de leite $\left(\mathrm{PL}^{\prime}\right)=176,8$ - 17,70 (TS1MAX) + 0,62 $\left(\mathrm{TS}_{1} \mathrm{MAX}^{2}\right)$ - 0,007 $\left(\mathrm{TS}_{\mathrm{MAX}}^{3}\right)$

Os dados apresentados na Tabela 3 referem-se à adequação da suposição de efeitos aleatórios, com os coeficientes do modelo. Na Figura 3, indica-se a produção predita pelo modelo ajustado.

TABELA 3. Modelo de regressão polinomial para previsão de produção por temperatura máxima do solo do pasto.

\begin{tabular}{lrrrrrr}
\hline & Coeficientes & Erro-Padrão & \multicolumn{1}{c}{$\mathrm{z}$} & $\mathrm{P}>|\mathrm{z}|$ & \multicolumn{2}{c}{ Intervalo de Confiança de 95\% } \\
\hline $\mathrm{T}$ & $-17,70548$ & 6,731614 & $-2,630$ & 0,009 & $-30,8992$ & $-4,5117$ \\
$\mathrm{~T}^{2}$ & 0,61779 & 0,225736 & 2,737 & 0,006 & 0,1753 & 1,0602 \\
$\mathrm{~T}^{3}$ & $-0,00705$ & 0,002504 & $-2,819$ & 0,005 & 0,0119 & 0,0021 \\
interc. & 176,77040 & 66,432520 & 2,661 & 0,008 & 46,5650 & 306,9757 \\
\hline
\end{tabular}

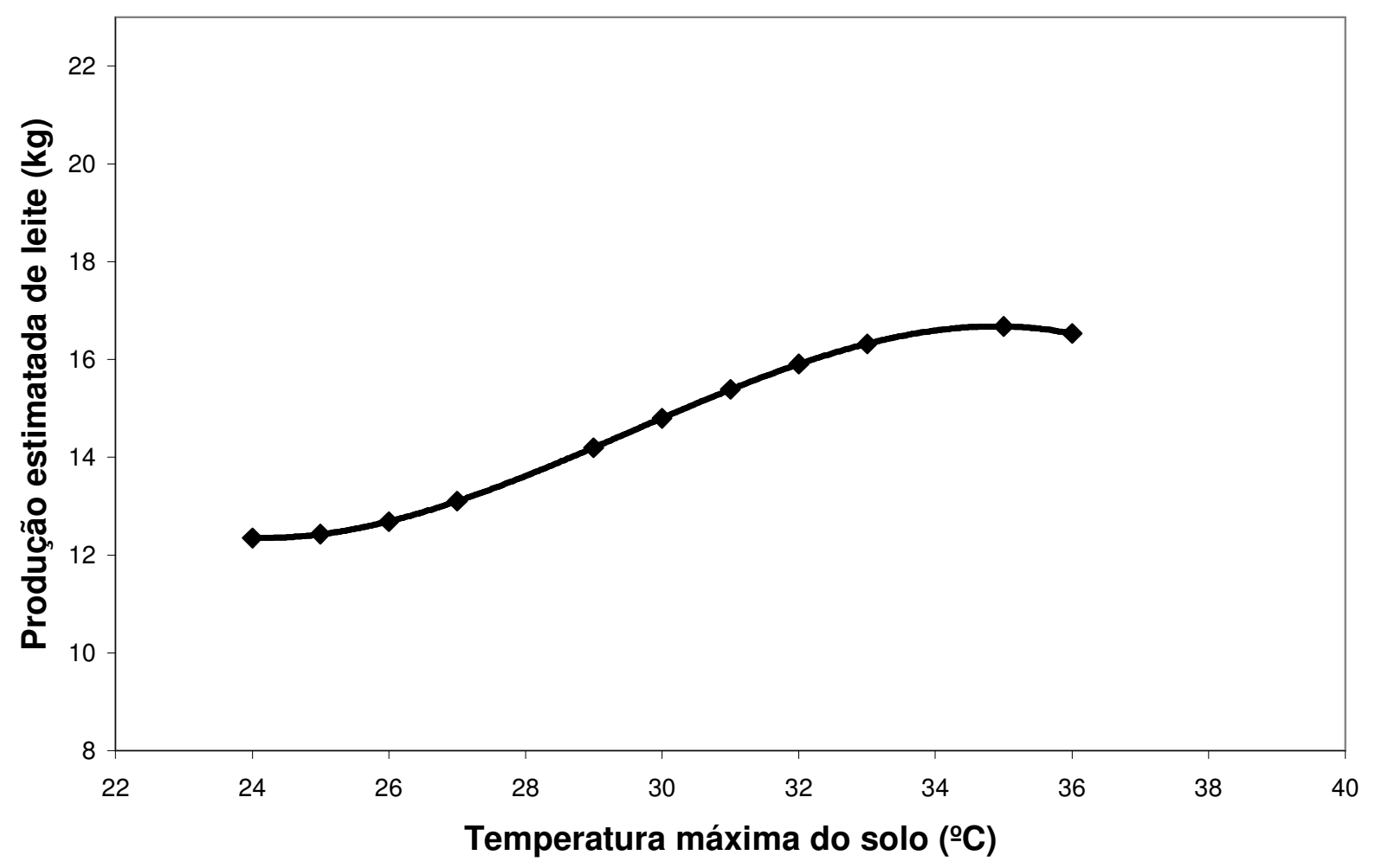

FIGURA 3. Valores preditos e observados pelo modelo da eq.(2), em função da temperatura máxima do solo do pasto. Limite de confiança de $95 \%$ para os coeficientes. 
Não foi encontrada nenhuma referência quanto ao efeito positivo da temperatura máxima de solo na produção de leite em vacas em lactação; entretanto, as temperaturas do solo apresentaram-se altas no período em que houve maior insolação e imediatamente anterior à precipitação pluviométrica durante o experimento. Esse fato reforça a suposição inicial dos resultados das curvas de interpolação, de que a influência mais importante na resposta de produção de leite das vacas sob os tratamentos e em pastoreio, foi a da precipitação pluviométrica diária.

\section{CONCLUSÕES}

Das análises realizadas, pode-se concluir que o tratamento A, utilizando o chuveiro associado à ventilação, não apresentou diferenças significativas e, mesmo em termos de efeitos (diferenças de médias), não trouxe ganho na produção de leite. Entretanto, há evidência da influência da precipitação, quando as vacas estavam no pasto, resultando em um acréscimo na produção quando as temperaturas estiveram entre 30 e $34^{\circ} \mathrm{C}$.

O modelo de previsão, em função da precipitação, mostrou-se viável por meio das análises exploratórias e de fácil utilização. $\mathrm{O}$ uso de índices que utilizam a temperatura ambiental, fora da amplitude observada (entre 24 e $36^{\circ} \mathrm{C}$ ), pode não ser adequado para este caso específico de vacas Jersey em semiconfinamento.

\section{REFERÊNCIAS BIBLIOGRÁFICAS}

BACCARI JÚNIOR, F.; JOHNSON, H.D.; HANH, G.L. Environmental hat effects on growth, plasma $\mathrm{t}$, and post heat compensatory effects on Holstein calves. In: CONGRESS OF SOCIETY OF EXPERIMENTAL BIOLOGY MEDICINE, 1983, Gainesville. Proceedings... Gainesville: Society of Experimental Biology Medicine, 1983. v.173, p.312-18.

BAÊTA, F.C. Instalações para gado leiteiro na região do mercosul. In: CONGRESSO BRASILEIRO DE BIOMETEOROLOGIA, 2., 1998, Goiânia. Anais... Goiânia: Sociedade de Biometeorologia, 1998. p.162-73.

BIANCA, W. Reviews of the progress of dairy science. Section: Physiology of cattle in hot environment. Journal of Dairy Research, Cambridge, v.32, p.245-92, 1965.

BIANCA, W. Thermorregulation. In: Hafez, E.S.E. Adaptation of domestic animals Philadelphia. Londres: Lea \& Fabiger, 1973. p.97-118.

BUCKLIN, R.A.; BRAY, D.R. The American experience in dairy management in warm and hot climates. In: SIMPÓSIO BRASILEIRO DE AMBIÊNCIA NA PRODUÇÃO DE LEITE, 1., 1998, Piracicaba. Anais... Piracicaba: ESALQ, 1998. p.156-74.

DUKES, H.H. Fisiologia de los animales domesticos. Madrid: Aguilar, 1962. 335 p.

FEHR, R.L.; PRIDDY, K.T.; MCNEILL, S.G.; OVERHULTS, D.G. Limiting swine stress with evaporative cooling in the Southeast. Transactions of the ASAE, St. Joseph, v.26, n.12, p.542-5, 1983.

HAFEZ, E.S.E. Adaptación de los animales domesticos. Barcelona: Editorial Labor, 1973. 563 p.

HUBER, H. Manejo de animais em sistema de estabulação livre visando maximizar o conforto e a produção. In: CONGRESSO BRASILEIRO DE GADO LEITEIRO, 2., 1995, Piracicaba. Anais... Piracicaba: ESALQ, 1995. p.41-68.

HUBER, J.T. Relação entre nutrição e "stress" térmico em gado leiteiro. In: SIMPÓSIO SOBRE PRODUÇÃO ANIMAL, 6., 1989, Piracicaba. Anais... Piracicaba: FEALQ, 1990. p.63-5. 
JOHNSON, H.D. Environmental temperature and lactation with special reference to cattle. International Journal of Biometeorology, Lisse, v.9, p.103-16, 1965.

JOHNSON, R.A.; WICHERN, D.W. Applied multivariate statistics. New York: Prentice Hall, 1998. $235 \mathrm{p}$.

JONES, R.H. Longitudinal data with serial correlation: A State-Space Approach. Chapman \& Hall, 1993. $132 \mathrm{p}$.

LALONI, L.A. Produção de leite baseada no índice de temperatura equivalente revisado para gado estabulado em semiconfinamento. 1997. 107 f. Dissertação (Mestrado em Engenharia Agrícola) Faculdade de Engenharia Agrícola, Universidade Estadual de Campinas, Campinas, 1997.

MORAES JÚNIOR, A.C.P. Jersey, a raça eficiente. São Paulo: Associação Paulista dos Criadores de Gado Jersey, 1997. 43 p.

NÄÄS, I.A. Biometeorologia e construções rurais em ambiente tropical. In: CONGRESSO BRASILEIRO DE BIOMETEOROLOGIA, 2., 1998, Goiânia. Anais... Goiânia: Sociedade de Biometeorologia, 1998. p.63-73.

PICKERING, N.B. Operational stochastic meteorological models for nonpoint source pollution modeling (Mouse model). 1982. 125 f. Dissertação (Mestrado em Engenharia Agrícola) - Cornell University, Department of Agricultural Engineering, Ithaca, New York, 1982.

PIMENTEL GOMES, F.P. Curso de estatística experimental. Piracicaba: Nobel. 1987. 467 p.

SELYE, H. Stress without distress. New York: New American Library, 1975. 193 p.

ZAPPAVIGNA, P. Thermal behavior of animal houses in hot climate: experimental contributions to the theoretical approach. In: ASAE ANNUAL INTERNATIONAL MEETING, 2001, Chicago. St Joseph: ASAE, 2001. (Paper: n. 024110) 